\title{
Influence of Marital Status on Attitude of Midwives towards OSCE and Their Performance in the Examination in Akwa Ibom and Cross River States, Nigeria
}

\author{
Duke, Emon Umoe ${ }^{1}$, Mgbekem, Mary Achi ${ }^{1}$, Nsemo, Alberta David ${ }^{1}$, Ojong-Alacia, Mary Manyo ${ }^{2}$, Nkwonta Chigozie. \\ A. $^{3}$, Mobolaji-Olajide, O. M. ${ }^{3}$ \\ ${ }^{1}$ Department of Nursing Science, University of Calabar, Nigeria \\ ${ }^{2}$ Department of Nursing, Madonna University, Elele, Nigeria \\ ${ }^{3}$ Department of Nursing, College of Medicine, Lagos State University, Nigeria \\ Correspondence: Duke, Emon Umoe, Department of Nursing Science, University of Calabar, Nigeria
}

Received: May 6, 2015 Accepted: May 14, 2015 Online Published: June 3, 2015

doi:10.11114/jets.v3i4.812

URL: http://dx.doi.org/10.11114/jets.v3i4.812

\begin{abstract}
This quantitative study investigated the influence of marital status on the midwives' attitude towards OSCE and how this affects their performance in the examination. Two hypotheses guided the study. $\mathrm{H}_{\mathrm{O} 1}$ sort to find out if there exist a significant influence of marital status of midwives on their attitude towards OSCE as well as performance in the examination and $\mathrm{H}_{\mathrm{O} 11}$ states: there is no significant joint influence of midwives' attitude and marital status on their performance in OSCE. Ex-post facto design was used to carry out the study. 502 midwives from 8 institutes of midwifery education in Akwa Ibom \& Cross River states were engaged in the study. Two validated instruments, OSCE stake holders' questionnaire (OSCEQ) and Achievement test on OSCE were used to collect data for the study. Data were analyzed using linear regression analysis of variance (ANOVA). The findings show that marital status significantly influences midwives' perception of OSCE. However, there is no significant influence of marital status on midwives' attitude towards OSCE. The implication of these findings is, it will be useful and helpful to midwife educators in counseling of new midwifery students on OSCE.
\end{abstract}

Keywords: attitude, performance, student midwives, OSCE, marital status, midwife tutors

\section{Introduction}

\subsection{Background of the Study}

The use of objective structured clinical examination (OSCE) as a method of evaluation for the midwifery programme in Nigeria was introduced by the Nursing and midwifery Council of Nigeria in 1990. OSCE is perceived to be effective because it encompass all the requirements of an objective. The use of OSCE as a method of evaluation has brought confidence on pupil midwives by reason of its objectivity. Midwifery students have gradually developed a positive attitude towards OSCE (Duke, 2010).

Attitudes are acquired dispositions to act in a particular way. Attitudes are expressed in actions. A man's attitude is directed by his perceptions (Hartsucker and Pickerling 2001) It is seen in this piece of work as the end product of perception and it manifest as behavior (Duke, 2010). A type of examination can be perceived; either as a source of satisfaction to human needs in terms of goal attainment educationally and in other fields of human endeavor or as a dangerous element emitting fear, anxiety and illness within the candidate. Attitudes have to do with complex processes of human responses to situations (Duke, 2010). The accuracy of a person's attitude has a major impact on his responses to given situations. It is on this premise the researchers seek to investigate if midwives' attitude towards OSCE affect their performance in the examination when their marital status is considered.

\subsubsection{Framework}

Tri component model of attitude was chosen to guide this study, Traver (1972) opined that attitude is comprised of three components, viz: the cognitive component, the affective component and the behavioral component. 
i) The cognitive component refers to a preposition that expresses the relationship between situations and attitudinal objects. According to Traver (1972) often times attitude were built on a large store of correct or incorrect information like some given by school mates on subjects or methods of examination.

ii) The affective components; this component according to Morris (1976), deals with feelings that accompany ideas, objects or persons. There are positive and negative dimensions to this component and the dimension of like and dislike is very crucial here. A student may dislike a particular subject in the school curriculum but like another.

iii) The behavioral component; this component is the predisposition for action. According to Traver (1972). there is a marked discrepancy between expressed and the actual behavior exhibited

Fig.1 below shows that when a belief is established (perception) emotions are aroused, desired action is taken, and judgment is made. Consequently when a candidate conceives an idea, (belief) she grows emotional ("feelings). The said feelings may be positive or negative and most often translated into action.

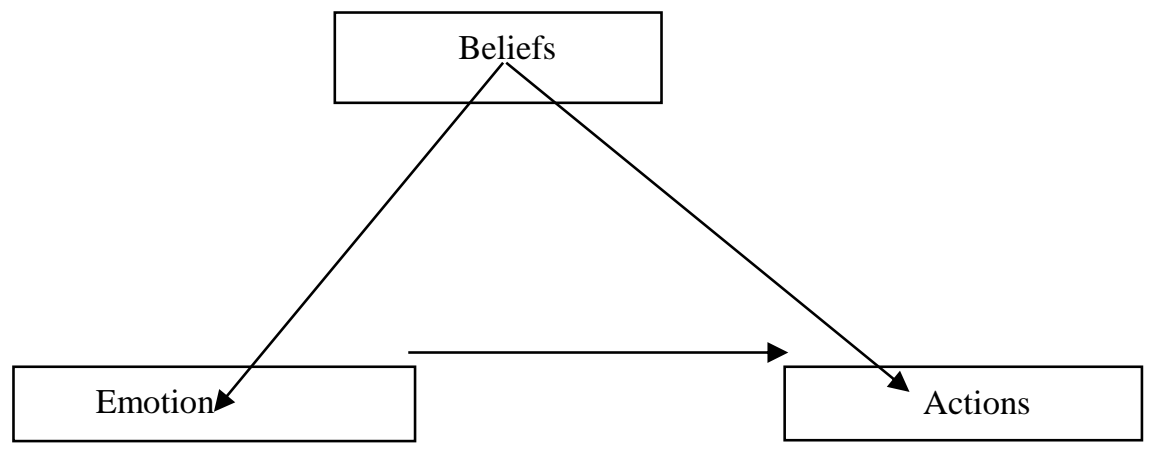

Figure 1. The Tri-Component Model of attitude

\subsection{Purpose of the Study}

The overall objective is to determine if midwives' attitude towards OSCE affect their performance when their marital status is considered.

Specifically the study seeks to:

i) Assess the extent to which attitude towards OSCE affect Midwives' performance in the examination when marital status is considered.

ii) Determine if there exists any joint influence of attitude and marital status on midwives' performance in OSCE.

iii) 1.3 Research Questions

iv) To what extent does the attitude towards OSCE affect midwives' performance in the examination when marital status is considered?

v) Do attitude and marital status of midwives have joint influence on their performance in the examination?

\subsection{Research Hypotheses:}

$\mathrm{H}_{\mathrm{O} \text { 1: }} \quad$ There is no significant influence of marital status of midwives on their attitude towards OSCE and their performance in the examination.

$\mathrm{H}_{\mathrm{O} \text { 11: }} \quad$ There is no significant joint influence of midwives' attitude towards OSCE and marital status on their performance in the examination

\section{Review of Related Literature}

Literature will be discussed under the following headings:

i) Attitude and academic performance

ii) Marital status academic performance

iii) Attitude of students towards OSCE and academic performance.

\section{1. Attitude and Academic Performance}

Attitude is a significant individual predictor of students' performance (Akubiro and Joshua (2002). The relationship between attitude and performance is consequent on reciprocal influence; attitude influences academic achievement and academic achievement influences attitude (Duke, 2010). Previous studies by Anagbogu (2005) and Obo (2004) revealed a non-significant effect of attitude on academic achievement. Amoo and Rohman (2004) explored 240 senior secondary school students' attitudes towards learning mathematics in the world of information technology in Lagos, the findings showed a non- significant difference in attitude of students towards mathematics on ground of gender. Previous study by 
Zeidner (1988) sought to establish the relationship between test attitude and test performance. Using a sample of 259 students, attitude and test data were matched for individual students by collecting attitude inventory according to the exact order of students' seating arrangement during test administration. Finding showed a non-significant relationship. Prawatt (1983) looked at the influence of attitude on performance of $2869^{\text {th }}$ graders in general mathematics and algebra; two kinds of measures were adopted which comprised of items that assessed the number of individually liked status variables such as self-esteem and attitude towards classroom environment. The result revealed that students with high level of attitude towards mathematics performed better than those with low level of attitude.

Cross (1981), noted that a positive attitude towards education appears to be infectious. He opined that people develop interest on objects and issues from others around them. The closer the contagious person is to the potential learner the more likely the learner is to be influenced. Ukpong (2000) reported that attitude influences student's choices, responses, values, participation and commitment to educational activities. Attitude is directed by perception (Hart, Wirer and Pickerling, 2001), it is the end product of perception and manifest as behavior while perception is influenced by motive (Millikan 2003). Vanderbeeken and Weber (2002) observed that attitudes are products of perception and if an individual's feelings are positive towards an event, his behavior will be positive. Cuttance(1980) did a six subject survey using data from the second International Association for the Evaluation of Educational Achievement (IEA) . He found a non-significant correlation between students' attitude their academic performance. A person's attitude is strangely influenced by his perception while attitude on the other hand form a link between knowledge and practice (Newble 1999).

\subsection{Marital Status and Academic Performance}

Etaugh and Nekolny (1990) assessed the effect of marital status and academic performance on forty-eight each of female and male adults, evaluated person on two hundred and forty seven (247) point bipolar scales. Each subject rated one of four students. The student was portrayed as married, widowed, divorced and never married. Married students were viewed more favorably than divorced, widowed or never married. Married students' mean score was higher. The findings showed that married students had a better significant positive relationship with regards to performance than the divorced, widowed or never married group. Stein (2006) examined the influence of marital status on academic performance, he reported a non-significant influence and concluded that marital status has no significant influence on academic performance. Coombs and Fawzy (2003) compared the differences in stress and academic performance between 61 married and unmarried students during the stressful years in medical school. Academic performance was measured each year by self-report and interviews with spouses. The result was that the stressors of medical school were more severe on the single students while the mean score for academic performance of the married students was higher. Moreover, stress level for formerly single students declined after marriage. The mean score of their academic performance also increased after marriage. In a previous study, public perception of the marital status varied; whether it had to do with the male or female but the married group was perceived more favorably than the unmarried group (Duberman, 2004). Blair (2001), assessed the perception of marital status among students of the University of Oklahoma and observed that never married were perceived more favorably than the married group. The married group was perceived more favorably than the widowed and the divorced group. In a study to examine perception of the personal and professional characteristics of individuals who vary in marital status; 50 females and 112 males rated the individual on a 207-point bi polar scale that described personality traits and professional performance characteristics. Each subject rated one of 8 persons either as male or female and either as married, widowed, divorced or never married. Etaugh and Maelstrom (2002), found that married individuals were evaluated more favorably than all groups of unmarried individuals, and widowed persons were rated more favorably than either divorced persons or never married with respect to perception.

In 2004, Etaugh and Petroski; using thirty (30) females and twenty five (25) males to examine the effect of marital status on academic performance found similar result to Etaugh and Nekolny (1990). The married group was viewed more favorably than those who were unmarried in terms of academic performance. One of the most consistent findings was that the married group, whether students, employed or unemployed generally performed better academically (Etaugh and Malstron 2002, Etaugh and Stern 2003, Etaugh and Petrosk 2004, Etaugh and Nekolny 1990).

\subsection{Attitude of Students towards Objective Structured Clinical Examination}

According to Duke, Ojong, Mgbekem, Oyira, Osaji, and Diepiri (2010) OSCE is a means of assessing clinical competence based on objective testing, through direct observations. It has the singular advantage of giving a wide coverage to the curriculum. OSCE provides external assessment of knowledge, skills and behaviours in the context of a low rate simulated clinical encounter (Tregunno, Norton, Smee, De Vries, Sebok, Van Denkerkof etal, 2014). Various studies have been conducted to determine perception, attitude of students towards OSCE and their performance in OSCE, Kemp, Flazarous and Kent (2005) ascertained if students considered OSCE a good method of practical 
examination, using 150 students as the sample size; the findings showed that students were in favor of the introduction of station testing skills as part of OSCE, and see it as a reliable device with a good capacity for discriminating between different categories of students. Jain, Delisa, and Campanolo () explored students' acceptance of OSCE as part of evaluation of child health clerkship 205 undergraduates from Ontario college of pharmacists formed formed the sample size. It was observed that there was an overwhelming acceptance of OSCE as an assessment instrument compared to other formats in terms of comprehensiveness (90\%), transparence(87\%), fairness (78\%), and authenticity (58-78\%). Schoolheim-klen, Walmslay, Haberts, Vanderand Manogue (2003) observed there is greater student satisfaction using OSCE as a form evaluation. Cohen, Rothman, Bulan and Rose (1996) in their study found that even resit students fine OSCE fair. Austin, O’Byrne, Pugsley, and Munoz (2003) reviewed the efficacy of OSCE as an evaluation tool; 218 medical students and 80 pharmaceutical students from three Universities in Canada were used as sample size. The findings of the study showed that OSCE was very effective. Furthermore the investigators as part of the study, held extensive consultations with stake holders of OSCE (lecturers in the institutions where OSCE was adopted as a form of assessment). The findings were positive, both lecturers and students preferred OSCE to the traditional oral/practical examination. Bowman (2003) put forth that OSCE very significantly improves oral practical examinations.

Most OSCE studies have focused on clinical aspects such as hand hygiene, or medication labeling, others have looked at other aspects of academic performance. However, no study could be found on influence of marital status on perception, and attitude towards OSCE and their performance in the examination. This is the first study to explore influence of marital status on perception and attitude of midwives towards OSCE and their performance in the examination.

\section{Method}

\subsection{Research Design}

Ex-post facto design was adopted for this study. According to Kerlinger, (1986: p. 97) ex-post facto design is defined as "a systematic empirical inquiry in which the scientist does not have direct control of the independent variable because their manifestation has already occurred or because inherently they cannot be manipulated, Inferences about relations among variables are made without direct variation of independent and dependent variables. The independent variables were studied in retrospect; in order to establish possible relationship with the dependent variable. The investigators did not have direct control of the independent variables; as their manifestation had already occurred. Inferences about relations among variables were made with direct variation of independent and dependent variables. They were concerned with ascertaining and establishing the status quo and facts at the time of the research and to use such facts to analyze data, interpret and extrapolate as well as draw inferences.

\subsection{Setting}

The setting for this study is comprised of the eight institutions for Post Basic midwifery education in Akwa Ibom and Cross River States; namely: School of midwifery, Anua-Uyo; School of Midwifery ,Iquita-Oron; School of midwifery, Ituk-Mbang and School of Midwifery Urua-Akpan in Akwa Ibom State . School of Midwifery Moore Road, Calabar; School of Midwifery, Moniaya-Ogoja; School of midwifery, Sacred Heart Hospital, Obudu; and Department of Nursing Science, University of Caladar; in Cross River State. Both states are in the south- south geopolitical zone of Nigeria. There are 18 local government areas in Cross River State and 31 local government areas in Akwa Ibom State.

\subsection{Population of the Study}

The population of this present study comprised of 532 midwives who graduated from the eight institutions of midwifery education within the period of study. But 502 midwives were available for the study.

\subsection{Sampling/Sample Size}

Purposive sampling method was used to select the 502 midwives who volunteered to participate in the study. This formed the sample size. This group of midwives considered most appropriate for the study because of their numerous encounter with OSCE during their days of training.

\subsubsection{Instrument}

Two validated instruments were used to collect data for this present study; OSCE stake holders' questionnaire and achievement text for OSCE. Content validity of the instruments was ascertained with the use of a table of specification for the achievement text while experts review and literature review were used to draw up items for the questionnaire. To ascertain the reliability of the instruments a text was carried to determine whether the instruments measure what they were supposed measure. Information gathered from the text was treated using Cronbach alpha method of ascertaining reliability. The reliability of various variables of the questionnaire stood at 0.68 for attitude and 0.66 for performance. 


\subsubsection{Ethical Consideration}

The study received ethical clearance from the institutional ethical review committee as well as individual nursing units of the hospitals where the respondents served. The participants were informed about their voluntary participation, their right to refuse to participate in the study at any given time. They were in addition assured that confidentiality of information would be maintained. Anonymity of participants was also ensured throughout the period of study by use of numbers and codes instead of names.

\subsection{Procedure for Data Collection}

The researchers/research assistants approached the midwives and informed them about the study, its purpose and benefits. Participants received the tools, wrote responses on them and returned them to the researchers or assistant as they waited. The researcher's checked the instruments for completeness or missing information in the fields. The assistants were trained in obtaining consent, distributing data forms and checking filled instrument for missing information. Out of 532 midwives who graduated from the institution within the period of study, 502 were available and participated in the study. 502 instruments were given out and all were collected back giving a return rate of 100\%. Data collected were treated using Analysis of variance and Regression analysis of prediction

\subsection{Procedure for Data Analysis}

The two hypotheses used for this study were stated in the null form thus:

$\mathrm{H}_{01}$ : There is no significant influence of marital status of midwives' on their attitude towards OSCE and their performance in the examination.

Independent variable: Midwives' Marital Status

Dependent Variables: Midwives' attitude towards OSCE and their performance in the examination.

Statistical Treatment: Analysis of Variance (ANOVA)

$\mathrm{H}_{011}$ : There is no significant joint influence of marital status and attitude of midwives' towards OSCE and their performance in the examination.

Independent variables: Marital Status and Attitude towards OSCE.

Dependent Variable: performance in OSCE.

\section{Results}

Influence of marital status on midwives' attitude towards OSCE and their performance in OSCE.

Table 1. Analysis of variance of influence of marital status on midwives' attitude towards OSCE and their performance in OSCE.

Anova Table 1

\begin{tabular}{|c|c|c|c|c|c|c|}
\hline Variables & Source Of Variation & Sum of Squares & $\mathrm{df}$ & Mean Square & $\mathrm{F}$ & Sig Of F \\
\hline \multirow[t]{3}{*}{ Attitude } & Between groups & 25.912 & 2 & 12.956 & 0.526 & 0.59 \\
\hline & Within groups & 12295.116 & 499 & 24.640 & & \\
\hline & Total & 12321.028 & 501 & & & \\
\hline \multirow[t]{3}{*}{ Performance } & Between groups & 426.572 & 2 & 213.286 & 1.440 & 0.23 \\
\hline & Within groups & 73914.512 & 499 & 148.125 & & \\
\hline & Total & 74341.084 & 501 & & & \\
\hline
\end{tabular}

$* \mathrm{P}<.05 ; \mathrm{f}_{3}, 495=882$

The results on table 1 show a non-significant influence of midwives' marital status on their attitude towards OSCE $\left(\mathrm{F}_{2}\right.$, $499=.526, \mathrm{p}>.05)$ and their performance $\left(\mathrm{F}_{2}, 499=1.44 ; \mathrm{P}>05\right)$ in the examination. The null hypothesis which states that: there is no significant influence of marital status on midwives" attitude towards OSCE and their performance in the examination was retained. The result implies that there is no significant influence of marital status on midwives' attitudes towards OSCE and their performance in OSCE.

Given the non- significant $\mathrm{F}$ - ratio, a multiple comparison text analysis was done using fisher's LSD to locate possible source of difference. The result of the analysis on table 2 shows that midwives' that were married had significant higher mean attitude of OSCE than midwives that were single $(\mathrm{t}=-30.00 ; \mathrm{P}<.05)$. Similarly midwives that were divorced/widowed had significant higher mean attitude of OSCE than midwives that were single $(\mathrm{t}=-2.10 ; \mathrm{P}<05)$. Other pair wise compassion between married and divorced / widowed was significant $(\mathrm{t}=-1.32 ; \mathrm{P}>.05)$.

Joint Influence of Midwives' Attitude towards OSCE and Marital Status on Their Performancs in OSCE.

The linear regression model was used to predict midwives' performance under joint influence of marital status, and 
attitude as criterion variables. Table 3 shows correlation among variables while table 4 shows the regression mode

Table 2. Inter Correlation amongst the Variables of the Study $(\mathrm{N}=502)$

\begin{tabular}{lllll}
\hline Variable Status & Performance & Perception & Attitude & Marital Status \\
\hline Performance & 1.00 & $.18^{* *}$ & $.15^{* *}$ & 0.6 \\
Attitude & & & 1.00 & .03 \\
Marital Status & & & & 1.00 \\
\hline
\end{tabular}

$* \mathrm{P}<.05 ; \mathrm{R}=0.23 ; \mathrm{R}^{2}=0.051$,

In table 2 the correlation coefficient is significant except marital status on performance with $\mathrm{R}^{2}=0.051$.

The result on table 4 shows that attitude and marital status are significant joint predictors of midwives' performance in OSCE $(\mathrm{F}=6.74 \mathrm{P}<.001)$. Attitude towards OSCE is seen to be the most significant predictor $(\mathrm{B}=.16$; $\mathrm{t}=2.54)$, followed by marital status $(B=.76, t=1.54)$ with a coefficient of determination $\left(R^{2}=0.051\right.$, meaning that any variation in midwifes performance in OSCE is accounted for by $5.1 \%$ variation in a combination of predictor variable.

Table 3a. Prediction of midwives performance in OSCE using joint influence of attitude towards OSCE and marital status as criteria.

\begin{tabular}{|c|c|c|c|c|c|}
\hline source of variation & Sum of squares & $\begin{array}{l}\text { Degree of freedom } \\
\text { (DF) }\end{array}$ & Mean square(MS) & $\mathrm{F}$ & Sign of E \\
\hline Regression & 3825.580 & 4 & 956.39 & 6.74 & $.000^{\mathrm{a}}$ \\
\hline Residual & 70515.59 & 497 & 1441.88 & & \\
\hline
\end{tabular}

Table 3b. Regression analysis of marital status and attitude towards OSCE and their performance in OSCE.

\begin{tabular}{llllll}
\hline Variables & B & Standard Error & $\begin{array}{l}\text { Bête } \\
\text { B }\end{array}$ & t & Sign of $t$ \\
\hline Attitude & 0.28 & 0.11 & 0.16 & 2.54 & 0.1 \\
Marital Status & -1.70 & 1.10 & -0.76 & -1.54 & 0.12 \\
\hline
\end{tabular}

* $\mathrm{P}<.05 ; \mathrm{R}=.23, \mathrm{R}^{2}=0.57$

The result on table 3 a shows that marital status and attitude are significant joint predictors of midwives' performance in OSCE $(\mathrm{F}=6.74 \mathrm{P}<.001)$. Hence the null hypothesis was rejected at .05 level of significance, while the inter correlation among variables was significant on performance with $\mathrm{R} 2=0.051$. This means that $5.1 \%$ of variability of midwives' performance in OSCE is jointly accounted for by the predictor variables of attitude and marital status. The regression model on Table $3 \mathrm{~b}$ also shows a contribution of each of the variables in the prediction of midwives performance in OSCE.

The result on table $3 \mathrm{~b}$ shows attitude towards OSCE as the most significant predictor $(\mathrm{B}=.16$; $\mathrm{t}=2.54)$ followed by marital status $(B=-.76 ; t=-1.54)$ with a coefficient of determination $(\mathrm{R} 2=0.051)$, meaning that any variation in midwives performance in OSCE is accounted for by $5.1 \%$ variation in a combination of predictor variables. Since the sign associated with regression weight (B) indicates the direction of prediction, it follows that prediction of performance in OSCE by attitude is positive, while that of marital status is in the reverse direction. This result means that the higher or more positive the attitude the higher the midwives' performance in OSCE, on the other hand the lower or less positive the attitude the lower the performance. As regards the marital status, the negative direction means that marital status has no significant influence on midwives performance in OSCE.

\section{Discussion}

Based on the findings, it seen that marital status does not have any influence on midwives' attitude towards OSCE and their performance in OSCE. These findings of this present study are in line with the findings of Cuttance (1980) which revealed non-significant correlation between attitude and their academic performance. Further analysis revealed that the married group had a significant higher mean attitude towards OSCE than the single group similarly among the single group midwives who were divorced or widowed had significant higher mean attitude towards OSCE than the never married. Other pair wise comparison between the married midwives and the single groups who were once married (widowed and divorced) mean performance was found to be insignificant. This result is in consonance with the findings of Prawatt (1980) whose findings revealed a significant mean effect as well as a significant unvaried effect; showing that the students with high level of attitude towards mathematics performed better than those with low level of attitudes. This finding of this study was similar to that of Etaught and Maelstrom (2002) .which revealed that married individuals were evaluated more favorably than all groups of unmarried individuals, and widowed persons were rated more favorably than either divorced or never married. The findings are also in consonance with that of Coombs and Fawzy (2003). This showed that the mean score for academic performance of the married medical students was higher. Moreover the stress level for formerly single students declined after marriage; the mean score of their academic 
performance also increased.

The findings of this study are at variance with the work of Bliar (1993) which revealed that the never married group was perceived more favorably than the married group. A major factor that may have contributed to the married group being perceived more favorably is the fact that a major need (companionship/marriage) has been met. The married candidate is more focused in her/his academic pursuit. Academic achievement to the married is not only expressed in intrinsic gratification but fulfillment for the entire loving family Duke (2010). Widowed persons would be among the rank of the married was it not for circumstances beyond their control: which sometimes may lead to disperse Duke et al, (2010).

Joint influence of attitude towards OSCE and marital status as joint predictors of their performance in OSCE. Findings show the contribution of each of the variables in the prediction of midwives' performance in OSCE. Attitude was the most significant predictor $(B=16: t=2,54)$, followed by marital status $(B=-76: t=-1,54)$ with coefficient of determination $\left(\mathrm{R}^{2}=\right.$, 051), it follows that prediction of performance in OSCE by attitude and marital status is significantly positive. The finding of this study agrees with the finding of Vanderbeeke and Waber (2002) which state that a positive attitude enhances academic achievement. The findings are in consonance with the accession of Traveler (1972) which state that often time's attitudes are built on large store of information. These findings are in line with that of Etaugh and Petroski (2004), who opined that the married group was viewed more favorably than those who were unmarried in terms of academic performance.

The possible reason why attitude and marital status can jointly predict performance could be due to the influence of perception. If midwives have a positive perception of OSCE this is bound to influence a positive attitude towards OSCE; thus enhancing good performance in OSCE.

\section{New Knowledge}

New knowledge added to body of knowledge from this study is that attitude towards OSCE and marital status are joint predictors of performance in OSCE

\section{Recommendations}

1. Since all that is required about objectivity is found in OSCE: the Nursing \& Midwifery Council of Nigeria should consider OSCE as a form of evaluation for other programs organized by the council.

2. OSCE has the singular advantage of giving a wide coverage to the curriculum; programs with a wide content like the general nursing curriculum should be reviewed and set in modules for easy usage.

Clinical nursing implications: The findings of study will useful to clinical instructors when grooming students in skill laboratory or in the clinical area.

\section{Acknowledgements}

We are indebted to all the participants in this study. Special thanks go to the dean of clinical sciences, Dr. Adewuya for his constant support and guidance. We are grateful to Mr. Afolabi Soaga for his immense contribution to this work. Above all we return all glory to God for his faithfulness.

Conflict of interest and source of funding - none declared

\section{References}

Akubiru, I. M., \& Joshua, M. T. (2002). Self-concept attitude and achievement of secondary students in science in Southern Cross River State. Nigeria. Online the African symposium, 4(1). http://www2.ncsu.edu/nesu/aern/seksien\&htm! 30-6-2007

Amoo, S. A., \& Rohman, M. A. (2004). Secondary school students' attitude of learning of mathematics. Akale, M. A. J. (Ed). In the world of information technology: implication for mathematics teachers and teacher preparation. Proceedings of the $45^{\text {th }}$ Annual conference of STAN. 175-182.

Anagbogu, G. E. (2005). Path analysis model foe correlates of Secondary school students' performance in financial accounting in southern education zone of Cross River State, Nigeria. Unpublished M.Ed. Thesis. Faculty of Education, University of Calabar, Calabar, Nigeria.

Bliar, N. (2001). Perception of marital status among students of university of Oklahoma. Journal of Family issues. 14(2), 189- 212.

Coombs, R. H., \&, Fawzy. (2003). The effect of marital status on stress and academic performance. Journal of Research in personality, 37, 319-338.

Cross, K. P. (1981). Adult learners, san francizes: Jossey: Bass publishers 
Cuttance, K. P. (1980). Affective factors jn the mediation of background effects on cognitive performance. Studies in educational evaluation, 6(1), 65-72. http://dx.doi.org/10.1016/0191-491X(80)90010-3

Duberman, R. (2004). Marital status and public perception. Journal of marriage and family. 12(28), 3-90.

Duke, E. U., Ojong,I. N., Mgbekem, M. A., Oyira, E. .J, Osaji, T. A., \& Diepiri, B. B. (2010). Midwives perception of objective structured clinical examination(OSCE) and their performance in OSCE in Akwa Ibom and Cross River States; Nigeria. International Professional Nursing Journal. 8(2), 7-12.

Duke. E. U. (2010). Graduate Midwives Perception And Attitude Towards Objective Structured Clinical Examination (OSCE) And their Performance In The Examination, in Akwa Ibom and Cross River States, Nigeria. Unpublished $\mathrm{PhD}$ Dissertation, Faculty of Education, University Of Calabar, Calabar, Nigeria.

Etaugh, C., \& Nekolny, K. (1990). Marital status and academics performance. Sex Poles, 23(6), 70-78.

Etaugh, C., \& Petrosk, 1. (2004). Marital status and academic performance. Journal of family Issues, 7(2), 89-99.

Etaugh, C., \& Stein, T. (2003). Effect of marital status on academic performance. Sex Roles, 21(3), 55-65.

Ginsburg, L. R., Tregunno, D., Norton, P, G., Smee, S., Veris, I., Sebok, S, S., VanDenKerkhof, E. G., Luckar-Flude, M., \& Medves, J. (2014). Developing and testing of an objective structured clinical exam (OSCE) yo assess socio-cultural dimensions of patient safety competency. BMJ mar, 24(3), 188-194. http://dx.doi.org/10.1136/bmjqs-2014-003277

Hart, K. E., Wiker, C., \& Pickerling J. A. (2001). A survey of medical students views about the purpose and Furness of OSCE, medical education, 36(9), 879-886.

Kemp, A., Flazarous, J., \& Kent, E. (2005). Reliability and validity of an objectives structured clinical examination for physiotherapy students. Journal of allied health, 32, 266-9

Millikan, R., Varieties of meaning, (2002) NICOD lectures, Cambridge: Macmillan press, 2003.

Morris G. Psychology. (1976 ). An introduction, Engle wood. Cliff: New Jersey: prentice- hill Inc

Obo, F. E. (2004). Some students' personal variables as predictors of mathematics achievement, in secondary schools in central Cross River State, Nigeria. Unpublished M.Ed. Thesis. Faculty of Education, University of calabar, Calabar, Nigeria.

Prawatt, R. S. (1983). Attitudinal differences between students in general mathematics and Algedra. Journal of educational research 76(4), 215-220.

Stein, C. K. (2006). Effect of marital status on public perception. Journal of marriage and family, 10(2), 77-96.

Traver, P. D. (1972). Essentials of learning (4 $4^{\text {th }}$ Ed). New York: Wiley.

Vanderbeenken, R., \& Weber, E. (2002). Dispositional explanation of behavior. Behavior and philosophy, 30, 43-59.

Zeidner, M., (1988). Socio-cultural differences in attitudes towards scholastic ability examination. Journal of Educational Measurement, 25(1), 65-76. http://dx.doi.org/10.1111/j.1745-3984.1988.tb00292.x

\section{$(\mathrm{cc}) \mathrm{BY}$}

This work is licensed under a Creative Commons Attribution 3.0 License. 